\title{
Changes in the body size of black-veined white, Aporia crataegi (Lepidoptera: Pieridae), recorded in a natural population in response to different spring weather conditions and at different phases of an outbreak
}

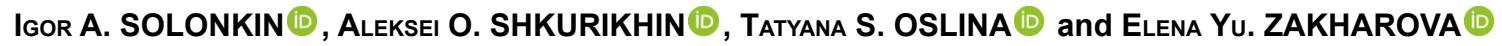 \\ Institute of Plant and Animal Ecology, Ural Branch, Russian Academy of Sciences, Ekaterinburg, 620144, Russia; \\ e-mails: igorsolonkin@yandex.ru, ashkurikhin@yandex.ru, oslina_ts@ipae.uran.ru, zakharova@ipae.uran.ru
}

Key words. Lepidoptera, Pieridae, Aporia crataegi, body size, phenotypic plasticity, temperature-size response, outbreak

\begin{abstract}
Changes in body size in response to environmental factors (especially temperature) is one of the crucial traits studied in connection with insect adaptation to climate change. However, current data on the strength and direction of temperature-size responses in Lepidoptera are inconsistent and the reasons for this are unclear. This study investigates the relationship between the adult size of Aporia crataegi L. (Lepidoptera: Pieridae) and spring weather conditions (temperature and rainfall) at different phases in its outbreak cycle (low population density or high abundance). The forewing area of $A$. crataegi, a univoltine and irruptive Lepidopteran species, was used as a proxy for overall body size. It was found that temperature in the last month before imago emergence (May) and temperature in the larval growth period following overwintering (April) had differing effects on imago size. The fact that the wing size of both male and female $A$. crataegi increased following higher temperatures in May corresponds with the converse temperature-size rule and is consistent with the predictions of life history theory for univoltine species. Conversely, while imago size decreased following higher temperatures in April, increased rainfall had a slightly positive effect on imago size. The wings of $A$. crataegi at the peak of abundance were larger than when sampled during periods of low population density, contradicting available data on changes in the body weight of $A$. crataegi recorded during outbreaks.
\end{abstract}

\section{INTRODUCTION}

Body size in insects is an important adaptive trait that correlates with various indicators of fitness: fecundity, mating success, dispersal ability, etc. (Honek, 1993; Tammaru et al., 2002; Kingsolver \& Huey, 2008; Dmitriew, 2011). Large adult size can only be achieved by faster growth or a prolonged growth period, both of which are associated with different risks and costs. Insects have previously been shown to be able to adaptively change their growth rate and development time, with specific strategies for maximising fitness either by achieving a large size or reducing development time (Nylin \& Gotthard, 1998; Gotthard, 2008; Dmitriew, 2011). Simultaneously, the duration of development and growth rate depend on environmental temperature in conjunction with the quantity and quality of available food (Chown \& Nicolson, 2004). Thus, the size of adult insects varies in response to both temperature and diet.

Ectotherms tend to follow the temperature-size rule, whereby body size at maturity decreases with increasing temperature (Atkinson, 1994). Although many insects conform to these growth characteristics, the opposite pattern can be found in some species (Angilletta et al., 2004;
Horne et al., 2015). The ultimate and proximate causes of a decrease in body size following an increase in environmental temperature have been discussed over the past few decades (Atkinson \& Sibly, 1997; Angilletta et al., 2004; Kingsolver \& Huey, 2008; Ghosh et al., 2013; Audzijonyte et al., 2018). Arthropods are recognised as having body size reduction mechanisms in response to increased temperatures that differ between species (Ghosh et al., 2013; Horne et al., 2019). Moreover, the direction and strength of temperature-size responses differ in males and females (Fischer \& Karl, 2010; Wilson et al., 2019) as well as in different populations (Kingsolver et al., 2007). This supports the hypothesis that the temperature-size response is adaptive, at least in terrestrial arthropods and can consequently be explained in terms of life history theory (Ghosh et al., 2013; Horne et al., 2015).

Recent research has shown that, while bivoltine or multivoltine species of terrestrial arthropods generally follow the temperature-size rule, univoltine species are more likely to exhibit strategies following the converse of this rule (Horne et al., 2015). This suggests that the fitness maximisation strategies of bi- and multivoltine species differ from 
those of univoltine species. Insects can benefit from faster growth rates at higher environmental temperatures and either grow to a larger size at maturity, shorten development time, or both. Achieving larger adult sizes may amplify fecundity, whereas a shortening in development time allows an increase in the number of generations per year (Honek, 1993; Nylin \& Gotthard, 1998; Dmitriew, 2011). Therefore, univoltine species are likely to obtain more benefits from reaching a larger size than from reducing development time, whereas for bi- and multivoltine species the converse is true. In accordance with this, one might expect the temperature-size response to be negative in bi- and multivoltine species (corresponding to the temperaturesize rule), but absent (Fischer \& Karl, 2010) or positive (Horne et al., 2015; Wilson et al., 2019) in univoltine species, corresponding to the converse temperature-size rule.

While lepidopterans are one of the most popular subjects in studies on phenotypic plasticity within the life history theoretical framework (Nylin \& Gotthard, 1998; Gotthard, 2008; Boggs, 2009; Fischer \& Karl, 2010; Wilson et al., 2019 , etc.), data on the direction and strength of temperature-size responses in Lepidoptera to date are inconsistent and do not always correspond to patterns found in other terrestrial arthropods. In accordance with expectations, adult size decreases with increasing temperatures in some bi- and multivoltine species (Davidowitz \& Nijhout, 2004; Karl \& Fischer, 2008; Fischer \& Karl, 2010; Bauerfeind \& Fischer, 2013; Bowden et al., 2015; Klockmann et al., 2017), while in others, the opposite effect, an increase in size, is observed (Gibbs et al., 2011a; Mega, 2014; Wilson et al., 2019). In many univoltine species, larger adults develop at higher temperatures (Beckwith, 1982; Kamata et al., 1995; Fenberg et al., 2016; Juhasz et al., 2016; Davies, 2019; Wilson et al., 2019), while in others, as above, the converse outcome is observed (Miller, 1977; Palanichamy et al., 1982; Fischer \& Karl, 2010; Barton et al., 2014). Reasons for the inconsistent and diverse nature of temperature-size responses in various species, and even in different populations of the same species, is puzzling mainly due to insufficient data for the various life histories. Data describing temperature-size responses in univoltine irruptive species (i.e., capable of outbreaks) are virtually absent.

In addition to temperature, insect size at maturity in natural populations depends on a variety of environmental conditions, most notably the quality and quantity of food. Irruptive species of forest Lepidoptera as a rule face food scarcity due to the gradual defoliation of host plants during their outbreaks (Isaev et al., 2001; Klemola et al., 2004; Myers \& Cory, 2013; Isaev et al., 2017), which may be expected to lead to decreases in growth rate and adult body size (Chown \& Nicolson, 2004). However, body size changes in the course of outbreak cycles depend on other conditions besides food. For example, high larval rearing density can stimulate caterpillar growth, producing larger imagoes (Isaev et al., 2001; Atterholt \& Solensky, 2010). Body size variation during outbreaks can be grouped into two types, which are sometimes assumed to correspond to different outbreak strategies (Klemola et al., 2004; Isaev et al., 2017). In some species (e.g., Siberian silk moth Dendrolimus sibiricus Tshetv. and western tent caterpillar Malacosoma californicum Packard), body weight increases along with a rise in population density (Isaev et al., 2001, 2017; Myers \& Cory, 2013). In other species (autumnal moth Epirrita autumnata Borkhausen, bordered white Bupalus piniarius L. and gypsy moth Lymantria dispar L.) increases in abundance lead to rapid decreases in body size: adults or pupae are smaller in outbreak years and larger during periods of low population density (Carter et al., 1991; Isaev et al., 2001, 2017; Klemola et al., 2004; Myers \& Cory, 2013).

The amount of precipitation also may bring about changes in the quality and quantity of food for Lepidoptera. In particular, the productivity and leaf biomass of deciduous trees in temperate forests increase with increase annual precipitation (Fang et al., 2005; Lie et al., 2018). Nevertheless, the influence of precipitation on foliage quality is ambiguous. On the one hand, an increase in rainfall leads to a decrease in the nitrogen and free amino acid content of plant tissues, as well as a higher water content. Thus, foliage quality should decline as rainfall increases. On the other hand, along with this, the production of plant chemical defences and leaf toughness decreases. This may lead to an increase in foliage quality, especially for polyphagous species that are less tolerant of secondary compounds (Huberty \& Denno, 2004; Gely et al., 2020). Data concerning precipitation effects on leaf-chewing insects, which include many relatively large species of Lepidoptera, are ambiguous and inconsistent. In some cases, the caterpillar's overall fitness is greater and, probably, their size is larger when rainfall deficiency is moderate (e.g., Gutbrodt et al., 2011; Bauerfeind \& Fischer, 2013; Couture et al., 2015). In other cases, the opposite pattern is reported (e.g., Inbar et al., 2001; Gibbs et al., 2011a, b).

This study aims to investigate the differences in adult size of a univoltine and irruptive species of Lepidoptera in response to changes in environmental temperature, rainfall and outbreak cycle phases.

\section{MATERIALS AND METHODS}

\section{Study system}

The black-veined white Aporia crataegi L. (Lepidoptera: Pieridae) is a large and univoltine (sometimes semivoltine in the northernmost areas of their range) butterfly which occurs throughout the Palearctic (Tatarinov \& Dolgin, 1999; Gorbunov \& Kosterin, 2003; Merrill et al., 2008). It is one of a few irruptive (i.e., capable of outbreaks) species of butterflies (Kuznetsova \& Palnikova, 2014; Isaev et al., 2017). The leaf-chewing caterpillars feed on ligneous Rosaceae and Ericaceae plants (Baranchikov, 1987). According to our observations, in the Middle Urals, larvae overwinter as II-III instars, then exit hibernation in mid-late April and begin to feed mainly on bird cherry (Prunus padus L.) and more rarely on mountain ash (Sorbus aucuparia L.) and Siberian crab apple (Malus baccata (L.) Borkh.) (Zakharova et al., 2020). During this feeding period, in which caterpillars moult to instars IV and later V (final), their body weight increases by two orders of decimal magnitude. The pupal stage lasts 15 to 25 days, with the first imago emerging between late May and mid June depending on spring weather (Table 1). 
Table 1. Summary of the statistics for spring weather, dates of the beginning of the imago flight, sample sizes and forewing area of $A$. crataegi in 2007-2020.

\begin{tabular}{|c|c|c|c|c|c|c|c|c|c|c|}
\hline \multirow{2}{*}{ Year } & \multicolumn{2}{|c|}{ Temperature $\left({ }^{\circ} \mathrm{C}\right)$} & \multicolumn{2}{|c|}{ Rainfall (mm) } & \multicolumn{2}{|c|}{$\begin{array}{l}\text { Date of the beginning } \\
\text { of the imago flight }\end{array}$} & \multicolumn{2}{|c|}{$\begin{array}{l}\text { Number of } \\
\text { specimens }\end{array}$} & \multicolumn{2}{|c|}{ Forewing area $\left(\mathrm{mm}^{2}\right) \pm \mathrm{SE}$} \\
\hline & April & May & April & May & Males & Females & Males & Females & Males & Females \\
\hline 2007 & 4.9 & 10.7 & 68 & 102 & unknown & unknown & 57 & 29 & $300.0 \pm 3.8$ & $334.7 \pm 7.1$ \\
\hline 2008 & 4.4 & 10.6 & 5 & 66 & unknown & unknown & 53 & 9 & $288.0 \pm 3.0$ & $339.4 \pm 9.3$ \\
\hline 2010 & 6.1 & 13.5 & 16 & 30 & unknown & unknown & 86 & 122 & $295.2 \pm 2.7$ & $339.6 \pm 3.1$ \\
\hline 2011 & 4.5 & 11.5 & 40 & 52 & unknown & unknown & 54 & 293 & $287.4 \pm 3.1$ & $323.0 \pm 2.1$ \\
\hline 2012 & 8.2 & 13 & 59 & 40 & unknown & unknown & 45 & 132 & $284.9 \pm 3.9$ & $335.8 \pm 2.9$ \\
\hline 2013 & 4.4 & 10.8 & 44 & 42 & 12.06 & 15.06 & 264 & 271 & $290.4 \pm 1.6$ & $325.1 \pm 2.4$ \\
\hline 2014 & 1.9 & 13.6 & 48 & 26 & 04.06 & 05.06 & 286 & 231 & $291.9 \pm 1.6$ & $335.1 \pm 2.4$ \\
\hline 2015 & 4.1 & 12.3 & 27 & 93 & 05.06 & 06.06 & 359 & 366 & $291.8 \pm 1.4$ & $332.0 \pm 1.7$ \\
\hline 2016 & 6.9 & 12.3 & 54 & 9 & 29.05 & 03.06 & 223 & 185 & $280.6 \pm 1.5$ & $327.5 \pm 2.6$ \\
\hline 2017 & 4.4 & 9.6 & 24 & 39 & 15.06 & 17.06 & 550 & 285 & $270.7 \pm 1.2$ & $306.7 \pm 2.4$ \\
\hline 2018 & 2.1 & 8.8 & 36 & 29 & 24.06 & 28.06 & 359 & 198 & $282.0 \pm 1.4$ & $311.3 \pm 2.2$ \\
\hline 2019 & 3 & 12.6 & 16 & 38 & 09.06 & 10.06 & 524 & 369 & $292.4 \pm 1.1$ & $333.5 \pm 1.5$ \\
\hline 2020 & 5 & 14 & 35 & 14 & 30.05 & 30.05 & 425 & 265 & $290.3 \pm 1.2$ & $325.0 \pm 1.8$ \\
\hline Mean & 4.6 & 11.8 & 36.3 & 44.6 & & & & & 286.2 & 326.3 \\
\hline
\end{tabular}

\section{Sampling}

The study area is located in the subzone of pre-forest-steppe pine-birch forests (Kulikov et al., 2013) in the Middle Ural region (Russia, Sverdlovsk region, near the village of Fomino, $\left.56^{\circ} 36^{\prime} \mathrm{N}, 61^{\circ} 03^{\prime} \mathrm{E}\right)$. The study area encompassed pine forest with low shrubs and herbaceous plants beneath, forest edges, and wet and dry meadows. As shown on the map (Fig. S1) and in the photographs (Fig. S2), the main sampling site consists of an elongated open space along a power line (about $2.5 \mathrm{~km}$ ), including adjacent forest edges and glades. The undergrowth in pine forests includes rosaceous trees and shrubs, predominantly bird cherry $P$. padus and mountain ash $S$. aucuparia; but Siberian crab apple $M$. baccata (sparse) and hawthorn Crataegus sanguinea Pall. (single plants) also occur. Various nectar-rich plants (Geranium, Trifolium, Knautia, Cirsium, Rubus) were abundant in open localities.

The samples of black-veined white butterflies were collected in 2007-2008 and 2010-2020 (Table 1). The population studied experienced outbreaks in 2010-2013 and low-density phases in 2007-2008 and 2014-2020. Starting from 2013, sampling was carried out throughout the entire butterfly flight period.

The mean monthly temperature and rainfall figures for April and May (Table 1) were provided by the meteorological station located at Verhnee Dubrovo, $16 \mathrm{~km}$ north of the study zone, which is freely available at http://www.pogodaiklimat.ru/history/28445. htm.

We selected wing area as a proxy for body size because, unlike body weight, it varies little throughout the life of the imago. We removed the wings of all individuals and took photographs of their ventral surface using a Canon Eos 450D digital camera. Along with the specimen, a scale bar was included in each image in order to avoid scale errors in wing area calculations. Landmarks on the left forewings were digitised using the software tpsDig 2.10 (Rohlf, 2006) at the distal tips of veins in accordance with pattern shown in Fig. 1. The left forewing area was calculated as the surface area being bounded by landmarks using the software tpsUtil 1.40 (Rohlf, 2008).

\section{Data analysis}

All analyses were carried out using the $\mathrm{R}$ software environment, version 3.6.3 (R Core Team, 2020). An ordinary leastsquares linear model was built for the analysis of the left forewing area, which included continuous predictors (temperature and rainfall in April and May), categorical factors (sex and the phase of outbreak) and interactions between the factor "sex" and the other predictors. Continuous predictors were standardised in order to allow correct interpretation of the main effects and interactions, as recommended by Schielzeth (2010). Model validation detected violations of assumptions concerning normal distribution and homoscedasticity of standard residuals. The inspection of the residuals' plots (Figs S3, S4) suggested that these violations were mainly due to negative skewness and an abundance of negative outliers, especially in females. For this reason, we used the robust MM estimator (Yohai, 1987) for model fitting. Since the output of the robust model was almost identical to that of the ordinary least-squares model (Tables S1, 2), there were no serious problems with violation of assumptions. Nevertheless, for describing the results we relied on the robust model. Separate estimates of regression coefficients for males and females were extracted from the full model by means of the emmeans package (Russell, 2020). The final model was obtained by eliminating non-significant interactions from the full robust model. The robust coefficient of determination was calculated according to a method consistent with Renaud \& Victoria-Feser (2010). The post-hoc comparisons were performed using the Tukey test in the multcomp package (Hothorn et al., 2008).

\section{RESULTS}

The final robust linear model of the $A$. crataegi wing area data using sex, outbreak phase and spring weather condition as predictors was significant $\left(\chi^{2}=3310\right.$; $\mathrm{df}=8$; $\mathrm{p}<$ 0.001 ; adjusted robust $\mathrm{R}^{2}=0.382$ ). The wing size of black-

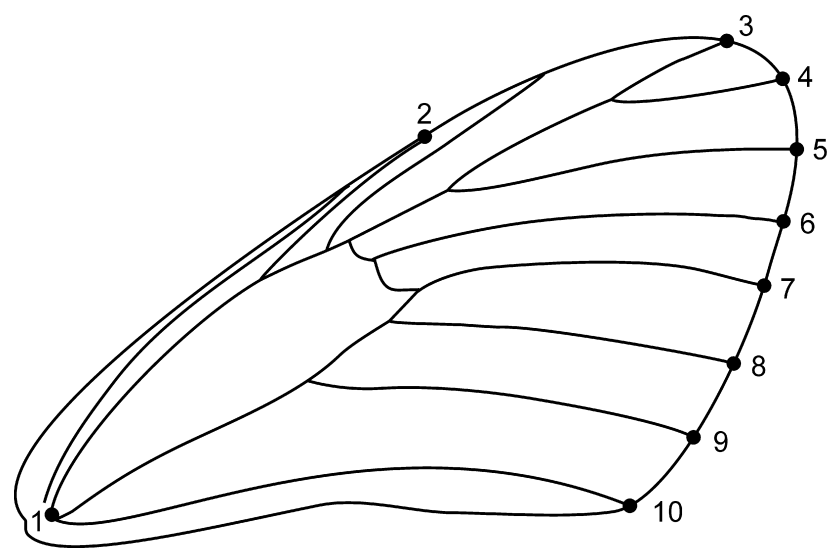

Fig. 1. Diagram of the forewing of $A$. crataegi indicating the positions of the different landmarks. 
veined white butterflies was significantly dependent on all of the variables included in the analysis except April rainfall (Table 2). Of the predictors, aside from sex, the May temperature had the greatest influence on wing area. We found that wing size increased as the environmental temperature in May increased (Fig. 2a, Tables 2, 3). Although the wing size of females increased with May temperature to a greater extent than that of males, this does not necessarily mean that female wing size is more responsive to temperature since the observed pattern may be a result of both the average value and variation in wing area in the female data sets being much larger than in those of the male (Table 1). In order to more accurately compare the temperature-size responses in different sexes, wing area was centred and scaled separately for males and females. The obtained standardised wing areas were used in the robust linear model construction. According to the output of this model, there was no significant difference between the sexes concerning changes in wing size in response to May temperatures (Table 4). Thus, the final wing size for females is greater following higher May temperatures than for males, but this effect is a result of the larger overall female size.

The environmental temperature in April compared to that in May had an opposite and weaker effect on the wing size of black-veined white butterflies (Fig. 2a, b). Although the decrease in wing area with increasing April temperatures was more conspicuous in males, it was also present in females as a weak tendency at the border of statistical significance (Tables 2, 3).

The May rainfall had a minor positive effect on adult wing size in both males and females (Tables 2, 3): the forewing area increased slightly following high rainfall (Fig. 2c). Wings of black-veined white butterflies sampled at the peak of abundance were on average $6.2( \pm 1) \mathrm{mm}^{2}$ larger than those sampled during low population density. The post-hoc comparison showed this difference to be significant $(\mathrm{z}=5.9 ; \mathrm{p}<0.001)$.

\section{DISCUSSION}

In this study, we investigated the strength and direction of changes in wing size in response to variations in spring weather and the outbreak phase in the univoltine and ir-
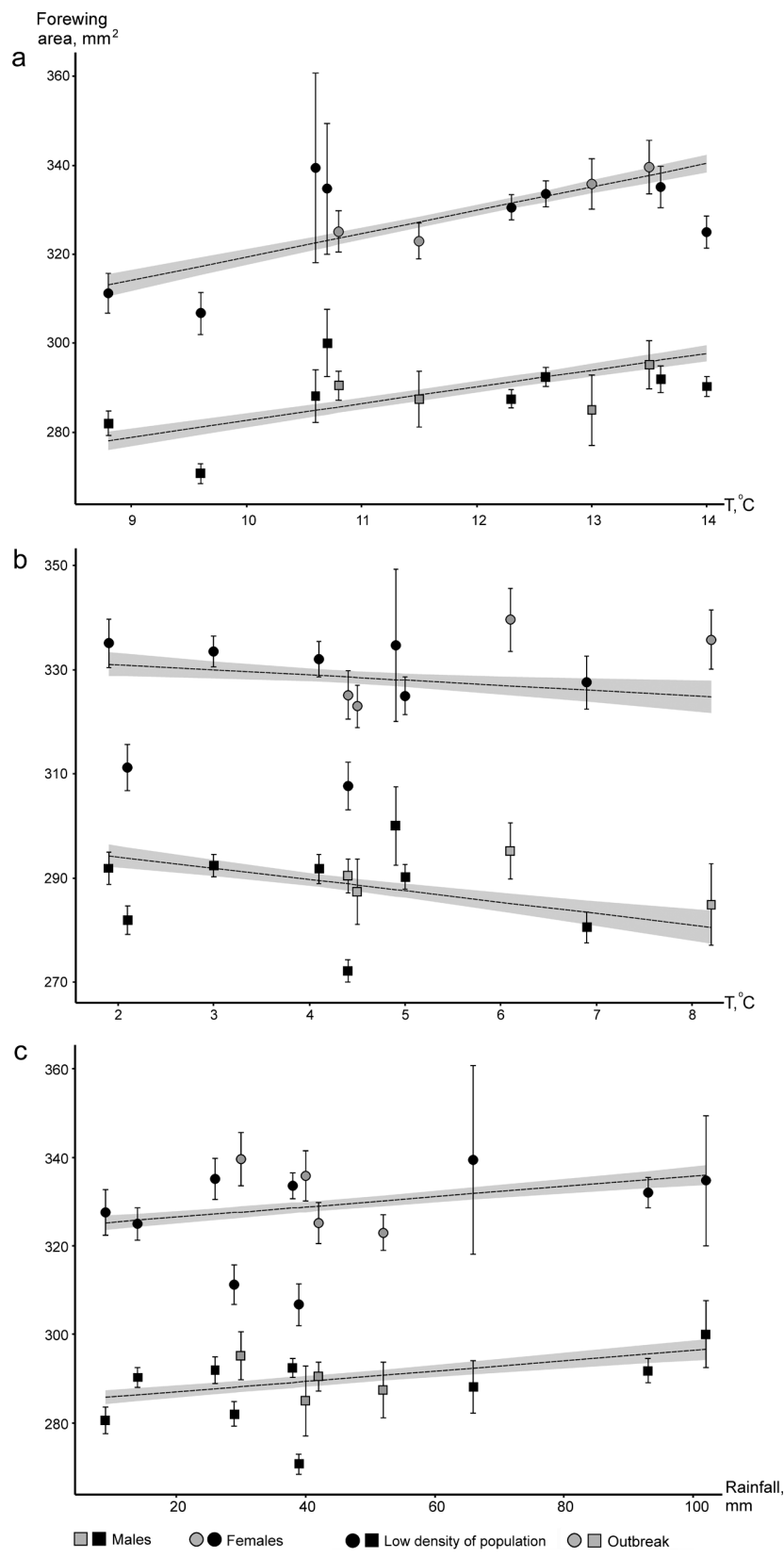

Fig. 2. The relationships between forewing area (mean and $95 \%$ confidence intervals) of male and female $A$. crataegi butterflies and a) temperature in May, b) temperature in April and c) rainfall in May. The regression lines and their $95 \%$ confidence intervals were obtained from the robust linear model using the emmeans package.

Table 2. Outputs of the full and final robust linear models for forewing area of $A$. crataegi (covariates are standardised, and sum-to-zero parametrisation for categorical factors is employed).

\begin{tabular}{|c|c|c|c|c|c|c|c|c|}
\hline \multirow{2}{*}{ Predictors } & \multicolumn{4}{|c|}{ Full model } & \multicolumn{4}{|c|}{ Final model } \\
\hline & $\beta \pm \mathrm{SE}$ & $95 \% \mathrm{Cl}$ (lower / upper) & $z$ & $p$ & $\beta \pm S E$ & $95 \%$ Cl (lower / upper) & $z$ & $p$ \\
\hline Intercept & $309.20 \pm 0.50$ & $308.23 / 310.17$ & 624.6 & $<0.001$ & $309.11 \pm 0.48$ & $308.17 / 310.06$ & 643.7 & $<0.001$ \\
\hline Sex & $19.40 \pm 0.50$ & $18.43 / 20.37$ & 39.2 & $<0.001$ & $19.71 \pm 0.38$ & $18.95 / 20.46$ & 51.3 & $<0.001$ \\
\hline Temperature (May) & $7.44 \pm 0.40$ & 6.66 / 8.22 & 18.6 & $<0.001$ & $7.46 \pm 0.40$ & $6.68 / 8.24$ & 18.7 & $<0.001$ \\
\hline Temperature (April) & $-2.35 \pm 0.43$ & $-3.18 /-1.51$ & -5.5 & $<0.001$ & $-2.38 \pm 0.42$ & $-3.21 /-1.55$ & -5.6 & $<0.001$ \\
\hline Rainfall (May) & $2.80 \pm 0.39$ & $2.03 / 3.56$ & 7.2 & $<0.001$ & $2.80 \pm 0.39$ & $2.04 / 3.56$ & 7.2 & $<0.001$ \\
\hline Rainfall (April) & $0.76 \pm 0.41$ & $-0.04 / 1.57$ & 1.9 & 0.06 & $0.75 \pm 0.41$ & $-0.04 / 1.55$ & 1.9 & 0.06 \\
\hline Outbreak & $-3.11 \pm 0.52$ & $-4.14 /-2.08$ & -5.9 & $<0.001$ & $-3.10 \pm 0.52$ & $-4.10 /-2.07$ & -5.9 & $<0.001$ \\
\hline Sex * Temperature (May) & $1.17 \pm 0.40$ & $0.39 / 1.95$ & 2.9 & 0.003 & $1.23 \pm 0.39$ & $0.46 / 2.00$ & 3.1 & 0.002 \\
\hline Sex * Temperature (April) & $1.03 \pm 0.43$ & $0.20 / 1.87$ & 2.4 & 0.02 & $0.89 \pm 0.39$ & $0.14 / 1.65$ & 2.3 & 0.02 \\
\hline Sex * Rainfall (May) & $-0.02 \pm 0.39$ & $-0.78 / 0.75$ & -0.05 & 0.96 & - & - & - & - \\
\hline Sex * Rainfall (April) & $0.07 \pm 0.41$ & $-0.73 / 0.88$ & 0.2 & 0.86 & - & - & - & - \\
\hline Sex * Outbreak & $0.53 \pm 0.52$ & $-0.50 / 1.56$ & 1.0 & 0.31 & - & - & - & - \\
\hline
\end{tabular}


Table 3. Outputs for the significant spring weather variables for males and females of $A$. crataegi (all estimates are based on the full robust linear model).

\begin{tabular}{|c|c|c|c|c|}
\hline Predictors & $\beta \pm \mathrm{SE}$ & $95 \% \mathrm{Cl}$ (lower / upper) & $z$ & $p$ \\
\hline Temperature in May (males) & $6.27 \pm 0.50$ & $5.29 / 7.24$ & 12.6 & $<0.001$ \\
\hline Temperature in May (females) & $8.61 \pm 0.63$ & $7.39 / 9.84$ & 13.8 & $<0.001$ \\
\hline Temperature in April (males) & $-3.38 \pm 0.58$ & $-4.51 /-2.24$ & -5.8 & $<0.001$ \\
\hline Temperature in April (females) & $-1.31 \pm 0.63$ & $-2.54 /-0.09$ & -2.1 & 0.036 \\
\hline Rainfall in May (males) & $2.81 \pm 0.53$ & $1.78 / 3.85$ & 5.3 & $<0.001$ \\
\hline Rainfall in May (females) & $2.78 \pm 0.57$ & $1.65 / 3.90$ & 4.8 & $<0.001$ \\
\hline
\end{tabular}

ruptive Lepidopteran species $A$. crataegi. The wing size of black-veined white butterflies was found to depend mainly on the temperature and rainfall in May, with the weather in April having much less of an effect. This anticipated result is consistent with results of previous studies according to which the temperature in the last month before the emergence of the imago has the greatest effect on their size (Fenberg et al., 2016; Wilson et al., 2019). There is a plausible and simple explanation for this: caterpillars gain most of their final weight (e.g., $90 \%$ in the tobacco hawkmoth Manduca sexta L.) during the last larval instar (Nijhout et al., 2006).

We established that, in common with a number of other univoltine species of Lepidoptera (Beckwith, 1982; Kamata et al., 1995; Fenberg et al., 2016; Juhasz et al., 2016; Davies, 2019; Wilson et al., 2019), adult size of blackveined white butterflies increases with rising environmental temperature during the last larval instar (Fig. 2a), which corresponds to that predicted by the converse temperaturesize rule. Consequently, the black-veined white takes advantage of the opportunity for rapid growth in order to grow to a larger final size, which is consistent with expectations from life history theory for univoltine species (Fischer \& Karl, 2010; Wilson et al., 2019). Along with this, adults not only reach larger sizes in warmer springs, but also emerge from pupae earlier (Table 1). Thus, like some other univoltine Lepidopteran species (Fenberg et al., 2016; Davies, 2019), the black-veined white seems to optimise both size at maturity and development time. Higher average temperatures $\left(12-14^{\circ} \mathrm{C}\right)$ during the last larval instar appear to allow $A$. crataegi both to maximise body size and minimise development time due to a higher growth rate. Low average temperatures $\left(9-10^{\circ} \mathrm{C}\right)$ decelerate growth of larvae, leading to both a reduction in adult size and retardation of emergence. Accordingly, adults are likely to have a higher potential fecundity in years with warmer springs. At the same time, the risk of death prior to maturity is reduced. In years with cooler springs, adults of black-veined white butterflies benefit from none of the above.

It is remains unclear why in several other univoltine species of Lepidoptera [grey arches Polia nebulosa Hufnagel (Noctuidae), Eupterote mollifera Walker (Eupterotidae), purple-edged copper Lycaena hippothoe L. (Lycaenidae) and common brown Heteronympha merope Fabricius (Nymphalidae)] the opposite pattern (adult size decreases with temperature increases) is recorded (Miller, 1977; Palanichamy et al., 1982; Fischer \& Karl, 2010; Barton et al., 2014). One may note that in the case of P. nebulosa the last larval instar occurs at the end of the vegetation season (Miller, 1977). The necessity to complete growth and pupate before the end of the vegetation season is evidently more important for reproductive success than reaching a larger size. Time-restricted growth periods could therefore promote a shortening of the development time in order to achieve maximum fitness (Nylin \& Cotthard, 1998; Fischer \& Karl, 2010; Dmitriew, 2011), thereby leading to a decrease in adult size with increasing temperature even in univoltine species. The other cause of inconsistency between expected and observed patterns could be a result of the evolutionary history of the species in question. It is possible that some species, which are strictly univoltine in nature within their area, remain potentially multivoltine and, under suitable conditions, can occasionally complete another generation, as in the case of L. hippothoe (Fischer \& Karl, 2010). It appears plausible that such latent multivoltine species, along with the ability to switch to being multivoltine, retain some adaptations of the multivoltine life history, including the negative temperature-size response.

While high temperatures in May resulted in an increase in wing size, high temperatures in April resulted in a slightly reduced wing area in black-veined white butter-

Table 4. Output of the robust linear model for forewing area of $A$. crataegi (forewing area was standardised separately for males and females, covariates are standardised, and sum-to-zero parametrisation for categorical factors is employed).

\begin{tabular}{|c|c|c|c|c|}
\hline Predictors & $\beta \pm S E$ & $95 \%$ Cl (lower / upper) & $z$ & $\mathrm{p}$ \\
\hline Intercept & $0.09 \pm 0.02$ & $0.06 / 0.12$ & 5.7 & $<0.001$ \\
\hline Sex & $-0.02 \pm 0.01$ & $-0.05 / 0.00$ & -1.7 & 0.10 \\
\hline Temperature (May) & $0.24 \pm 0.01$ & $0.21 / 0.26$ & 18.4 & $<0.001$ \\
\hline Temperature (April) & $-0.08 \pm 0.01$ & $-0.11 /-0.06$ & -5.9 & $<0.001$ \\
\hline Rainfall (May) & $0.09 \pm 0.01$ & $0.07 / 0.12$ & 7.3 & $<0.001$ \\
\hline Rainfall (April) & $0.02 \pm 0.01$ & $0.00 / 0.05$ & 1.8 & 0.08 \\
\hline Outbreak & $-0.10 \pm 0.02$ & $-0.13 /-0.06$ & -5.8 & $<0.001$ \\
\hline Sex * Temperature (May) & $0.01 \pm 0.01$ & $-0.01 / 0.04$ & 0.9 & 0.383 \\
\hline Sex * Temperature (April) & $0.04 \pm 0.01$ & $0.01 / 0.06$ & 2.8 & 0.005 \\
\hline
\end{tabular}


flies (Fig. 2a, b). Thus, the wing size of the black-veined white increases following high temperatures experienced during the last (V) larval instar and diminishes following high temperatures experienced during earlier (III-IV) larval instars. Although a similar pattern was recently reported in two species of Lycaenidae (Wilson et al., 2019), the possible sources of such a trend are not clear. The wing size depends greatly on the larval weight achieved before pupation (Nijhout \& Grunert, 2010), which, on the whole, as mentioned above, is gained during the last instar. Nevertheless, it is generally understood that a lower initial caterpillar weight at the beginning of the last instar can lead to a slight reduction in the final larval weight due to decreases in critical weight (Nijhout et al., 2006). Therefore, the reported pattern may be a result of the negative temperaturesize response of the III-IV larval instars of $A$. crataegi. This means that the sizes of the larvae in different instars in Lepidoptera may depend on temperature in different ways. However, the observed pattern is likely to have a simpler explanation. The caterpillars moult into the last instar earlier following a warmer April, and, therefore, their growth during the last instar would most likely occur under cooler conditions. Further experimental studies are required to fully understand the causes of the smaller adult sizes following high temperatures during caterpillar growth in the early instars.

Rainfall in May had a minor positive effect on the adult wing size of black-veined white butterflies (Fig. 2c). The data on the influence of rainfall on adult wing size of leafchewing phyllophagous species are very contradictory $(\mathrm{Hu}-$ berty \& Denno, 2004; Gely et al., 2020). The recorded relationship differs from what is previously described for other white butterflies feeding on cruciferous plants (Gutbrodt et al., 2011; Bauerfeind \& Fischer, 2013), but corresponds to the patterns found in several other leaf-chewing species of Lepidoptera (Inbar et al., 2001; Gibbs et al., 2011a, b). The reasons for the recorded effect remain unclear. To the best of our knowledge, there is no information in the literature indicating that May precipitation effects the quantity and quality of the foliage of the main host plant of the blackveined white butterfly, i.e., bird cherry. The dependence of the growth of $A$. crataegi caterpillars on the biochemical properties of host foliage also remains undescribed. Hence, currently only a speculative explanation can be proposed. The pupal mass of the black-veined white butterfly depends on food consumption efficiency rather than the mass of foliage consumed (Tarasova et al., 2015). Therefore, we assume that the recorded wing size enlargement of blackveined white butterflies due to increased May rainfall might have been associated with changes in foliage quality rather than an increase in leaf mass. The concentration of secondary compounds in leaves is known to decline with increased rainfall (Huberty \& Denno, 2004; Gely et al., 2020). Since the leaves of bird cherry contain many polyphenolic compounds (Vshivkova, 2009; Olszewska \& Kwapisz, 2011), it is possible that a decreased polyphenol content may have promoted food consumption efficiency, and, accordingly, the recorded weight gain of larvae of $A$. crataegi. Additional detailed research is needed for an improved understanding of the complex relationship between the adult size of leaf-chewing Lepidoptera and rainfall, both under experimental conditions and in natural populations.

Based on the results, wings of black-veined white butterflies during an outbreak are slightly larger than at a low population density. This contradicts the available data for this species. In particular, that the pupal weight at low population density is higher than during the period of high abundance (Kuznetsova \& Palnikova, 2014). This inconsistency may be attributed to the fact that different measures of body size were used. Since the pupal or adult weight closely correlates with potential fecundity, it can be considered as an indicator of the quantity of resources allocated for reproduction, whereas, wing size reflects the allocation of resources to flight and dispersal (Boggs, 2009; Rhainds, 2020). It is reported that Lepidoptera under conditions of moderate food shortage tend to invest more in wing growth than in body weight (Boggs \& Niitepõld, 2016; Tigreros \& Davidowitz, 2019). This prompts the assumption that wing size and body weight in black-veined white butterflies may vary differently in the course of an outbreak. It is possible that adult wing size increases during periods of high abundance, whereas body weight, according to Kuznetsova \& Palnikova data (2014), decreases. It is possible that the inference about the body size response to outbreaks may depend on which measure of size was selected by the researcher. Apparently, only a simultaneous study of the sizes of different body parts at different stages of the life history is likely to result in a better understanding of body size response to outbreaks.

The findings of our study support the hypothesis that body size increases with increase in temperature, commonly reported for terrestrial insects, may be the rule for univoltine species (Horne et al., 2015). It should be noted that physiological mechanisms of the temperature-size response at the current time are studied only in species in which size decreases with increase in temperature (M. sexta and Lycaena tityrus Poda, Davidowitz \& Nijhout, 2004; Karl \& Fischer, 2008). Therefore, it is necessary to study the physiological mechanisms of other types of temperature-size responses. The effect of temperature experienced during the growth of the last instar larva of $A$. crataegi on adult size can be well explained in terms of life-history theory, which additionally highlights the adaptive nature of the temperature-size response. The increase in adults size following heavy rainfall is likely to be due to an increase in host plant biomass. Other reported patterns (body size reduction following an increase in temperature during caterpillar growth following overwintering and wing enlargement occurring at the peak of population abundance) currently have no satisfactory explanations. The surprising (in the light of the previous data) increase in the wing size of $A$. crataegi during an outbreak signifies that the effects of population abundance on such adaptive phenotypic traits of insects remain poorly understood. Understanding these effects requires, on the one hand, a deeper knowledge of similar eruptive species, 
and, on the other hand, a wider coverage of various species and populations in order to reveal the full diversity of existing patterns.

ACKNOWLEDGEMENTS. We are grateful to A.V. Ivanov, P.V. Rudoiskatel', K.I. Fadeev, and students of the Ural Federal University for their help in collecting samples. Also, we thank L.A. Ivanova, N.M. Devi, V.V. Kukarskih for valuable comments on plant physiology, and two anonymous reviewers whose suggestions helped improve and clarify this manuscript. The long-term collection of field material, analysis and interpretation of results were done in accordance with the state assignment of the Institute of Plant and Animal Ecology, Ural Branch, Russian Academy of Sciences (No. AAAAA19-119031890087-7) and was funded by RFBR, project number 20-34-90006.

\section{REFERENCES}

Angilletta M.J., Steury T.D. \& Sears M.W. 2004: Temperature, growth rate, and body size in ectotherms: fitting pieces of a life history puzzle. - Integr. Comp. Biol. 44: 498-509.

AtKInson D. 1994: Temperature and organism size: a biological law for ectotherms. - Adv. Ecol. Res. 25: 1-58.

AtKinson D. \& SibLy R.M. 1997: Why are organisms usually bigger in colder environments? Making sense of a life history puzzle. - Trends Ecol. Evol. 12: 235-239.

Atterholt A.L. \& Solensky M.J. 2010: Effects of larval rearing density and food availability on adult size and coloration in monarch butterflies (Lepidoptera: Nymphalidae). - J. Entomol. Sci. 45: 366-377.

Audzionyte A., Barneche D.R., Baudron A.R., Belmaker J., Clark T. D., Marshall C.T., Morrongiello J.R. \& van Rijn I. 2019: Is oxygen limitation in warming waters a valid mechanism to explain decreased body sizes in aquatic ectotherms? — Global Ecol. Biogeogr. 28: 64-77.

BARANCHIKOV Yu.N. 1987: Trophic Specialization of Lepidoptera. ILiD SB AS USSR, Krasnoyarsk, 171 pp. [in Russian].

Barton M., Sunnucks P., Norgate M., Murray N. \& Kearney M. 2014: Co-gradient variation in growth rate and development time of a broadly distributed butterfly. - PLOS ONE 9(4): e95258, 8 pp.

BAuerfeind S.S. \& Fischer K. 2013: Testing the plant stress hypothesis: stressed plants offer better food to an insect herbivore. - Entomol. Exp. Appl. 149: 148-158.

BECKWITH R.C. 1982: Effects of constant laboratory temperatures on the Douglas-fir tussock moth (Lepidoptera: Lymantriidae). - Environ. Entomol. 11: 1159-1163.

BogGs C.L. 2009: Understanding insect life histories and senescence through a resource allocation lens. - Funct. Ecol. 23: $27-37$.

BogGS C.L. \& NiITEPÕLD K. 2016: Effects of larval dietary restriction on adult morphology, with implications for flight and life history. - Entomol. Exp. Appl. 159: 189-196.

Bowden J.J., Eskildsen A., Hansen R.R., Olsen K., Kurle C.M. \& Høye T.T. 2015: High-Arctic butterflies become smaller with rising temperatures. - Biol. Lett. 11: 20150574, 4 pp.

Carter M.R., Ravlin F.W. \& McManus M.L. 1991: Changes in gypsy moth (Lepidoptera: Lymantriidae) fecundity and male wing length resulting from defoliation. - Environ. Entomol. 20: $1042-1047$.

Chown S.L. \& Nicolson S. 2004: Insect Physiological Ecology: Mechanisms and Patterns. Oxford University Press, New York, $253 \mathrm{pp}$.

Couture J.J., Serbin S.P. \& Townsend P.A. 2015: Elevated temperature and periodic water stress alter growth and quality of common milkweed (Asclepias syriaca) and monarch (Danaus plexippus) larval performance. - Arthropod Plant Interact. 9: 149-161.

Davidowitz G. \& NiJhout H.F. 2004: The physiological basis of reaction norms: the interaction among growth rate, the duration of growth and body size. - Integr. Comp. Biol. 44: 443-449.

DAVIES W.J. 2019: Multiple temperature effects on phenology and body size in wild butterflies predict a complex response to climate change. - Ecology 100(4): e02612, 11 pp.

DMITRIEW C.M. 2011: The evolution of growth trajectories: what limits growth rate? - Biol. Rev. 86: 97-116.

Fang J., Piao S., Zhou L., He J., Wei F., Myneni R.B., Tucker C.J. \& TAN K. 2005: Precipitation patterns alter growth of temperate vegetation. - Geophys. Res. Lett. 32(21): L21411, 5 pp.

Fenberg P.B., Self A., Stewart J.R., Wilson R.J. \& Brooks S.J. 2016: Exploring the universal ecological responses to climate change in a univoltine butterfly. - J. Anim. Ecol. 85: 739-748.

FISCHER K. \& KARL I. 2010: Exploring plastic and genetic responses to temperature variation using copper butterflies. Clim. Res. 43: 17-30.

Gely C., Laurance S.G. \& Stork N.E. 2020: How do herbivorous insects respond to drought stress in trees? - Biol. Rev. 95: 434-448.

Ghosh S.M., Testa N.D. \& Shingleton A.W. 2013: Temperaturesize rule is mediated by thermal plasticity of critical size in Drosophila melanogaster. - Proc. R. Soc. (B) 280(1760): 20130174, 8 pp.

Gibbs M., Wiklund C. \& Van Dyck H. 2011a: Phenotypic plasticity in butterfly morphology in response to weather conditions during development. - J. Zool. 283: 162-168.

Gibis M., WiKLund C. \& VAN Dyck H. 2011b: Temperature, rainfall and butterfly morphology: does life history theory match the observed pattern? - Ecography 34: 336-344.

Gorbunov P.Yu. \& Kosterin O.E. 2003: The Butterflies (Hesperioidea and Papilionoidea) of North Asia (Asian Part of Russia) in Nature. Vol. 1. Rodina \& Fodio, Gallery Fund, Moscow, Chelyabinsk, $392 \mathrm{pp}$.

GotThARD K. 2008: Adaptive growth decisions in butterflies. Bioscience 58: 222-230.

Gutbrodt B., Mody K. \& Dorn S. 2011: Drought changes plant chemistry and causes contrasting responses in lepidopteran herbivores. - Oikos 120: 1732-1740.

HoNEK A. 1993: Intraspecific variation in body size and fecundity in insects: a general relationship. — Oikos 66: 483-492.

Horne C.R., Hirst A.G. \& AtKinson D. 2015: Temperature size responses match latitudinal size clines in arthropods, revealing critical differences between aquatic and terrestrial species. Ecol. Lett. 18: 327-335.

Horne C.R., Hirst A.G., Atkinson D., Almeda R. \& Kiørboe T. 2019: Rapid shifts in the thermal sensitivity of growth but not development rate causes temperature-size response variability during ontogeny in arthropods. - Oikos 128: 823-835.

Hothorn T., Bretz F. \& Westfall P. 2008: Simultaneous inference in general parametric models. - Biom. J. 50: 346-363.

Huberty A.F. \& DenNo R.F. 2004: Plant water stress and its consequences for herbivorous insects: a new synthesis. - Ecology 85: 1383-1398.

Inbar M., Doostdar H. \& Mayer R.T. 2001: Suitability of stressed and vigorous plants to various insect herbivores. Oikos 94: 228-235.

Isaev A.S., Hlebopros R.G., Nedorezov L.V., Kondakov Yu.P., Kiselev V.V. \& Sukhovol'skil V.G. 2001: Population Dynamics of Forest Insects. Nauka, Moscow, 374 pp. [in Russian].

Isaev A.S., Sukhovol'skiI V.G., Tarasova O.V., Palnikova E.N. \& Kovalev A.V. 2017: Forest Insect Population Dynamics, 
Outbreaks, and Global Warming Effects. Scrivener, Beverly, $286 \mathrm{pp}$.

Juhasz E., Vegvari Z., Toth J.P., Pecsenye K. \& Varga Z. 2016: Climate-induced changes in the phenotypic plasticity of the Heath Fritillary, Melitaea athalia (Lepidoptera: Nymphalidae). - Eur. J. Entomol. 113: 104-112.

KAMATA N. \& IGARASHI M. 1995: Relationship between temperature, number of instars, larval growth, body size, and adult fecundity of Quadricalcarifera punctatella (Lepidoptera: Notodontidae): cost-benefit relationship. - Environ. Entomol. 24: 648-656.

KARL I. \& FisChER K. 2008: Why get big in the cold? Towards a solution to a life-history puzzle. - Oecologia 155: 215-225.

Kingsolver J.G. \& Huey R.B. 2008: Size, temperature, and fitness: three rules. - Evol. Ecol. Res. 10: 251-268.

Kingsolver J.G., Massie K.R., Ragland G.J. \& Smith M.H. 2007: Rapid population divergence in thermal reaction norms for an invading species: breaking the temperature-size rule. J. Evol. Biol. 20: 892-900.

Klemola T., Ruohomäki K., Andersson T. \& Neuvonen S. 2004: Reduction in size and fecundity of the autumnal moth, Epirrita autumnata, in the increase phase of a population cycle. - Oecologia 141: 47-56.

Klockmann M., Karajoli F., Kuczyk J., Reimer S. \& Fischer K. 2017: Fitness implications of simulated climate change in three species of copper butterflies (Lepidoptera: Lycaenidae). - Biol. J. Linn. Soc. 120: 125-143.

Kulikov P.V., Zolotareva N.V. \& Podgaevskaya E.N. 2013: Endemic Plants of the Ural in the Flora of the Sverdlovsk Region. Goshchickij, Ekaterinburg, 612 pp. [in Russian].

Kuznetsova V.V. \& PaLniKova E.N. 2014: Factors affecting abundance dynamics of the thorn butterfly (Aporia crataegi L.) in suburban standing woods of Krasnoyarsk city. - Izv. S-Peterb. Lesotehn. Akad. 207: 49-59 [in Russian, English abstract].

LIE Z., XUE L. \& JACOBS D.F. 2018: Allocation of forest biomass across broad precipitation gradients in China's forests. - Sci. Rep. 8: 10536,8 pp.

Mega N.O. 2014: The adult body size variation of Dryas iulia (Lepidoptera, Nymphalidae, Heliconiinae) in different populations is more influenced by temperature variation than by host plant availability during the seasons. - Entomol. Sci. 17: 376-387.

Merrill R.M., Gutiérrez D., Lewis O.T., Gutiérrez J., Díez S.B. \& WiLSON R.J. 2008: Combined effects of climate and biotic interactions on the elevational range of a phytophagous insect. - J. Anim. Ecol. 77: 145-155.

Miller W.E. 1977: Weights of Polia grandis pupae reared at two constant temperatures (Lepidoptera: Noctuidae). - Great Lakes Entomol. 10: 47-49.

Myers J.H. \& Cory J.S. 2013: Population cycles in forest Lepidoptera revisited. - Annu. Rev. Ecol. Syst. 44: 565-592.

NiJHOUt H.F \& GRUNERT L.W. 2010: The cellular and physiological mechanism of wing-body scaling in Manduca sexta. - Science 330: 1693-1695.

Nijhout H.F., Davidowitz G. \& Roff D.A. 2006: A quantitative analysis of the mechanism that controls body size in Manduca sexta. - J. Biol. 5(5): 16, 15 pp.
Nylin S. \& GotThard K. 1998: Plasticity in life-history traits. Annu. Rev. Entomol. 43: 63-83.

OlszewsKa M.A. \& Kwapisz A. 2011: Metabolite profiling and antioxidant activity of Prunus padus L. flowers and leaves. Nat. Prod. Res. 25: 1115-1131.

Palanichamy S., Ponnuchamy R. \& Thangaraj T. 1982: Effect of temperature on food intake, growth and conversion efficiency of Eupterote mollifera (Insecta: Lepidoptera). — Proc. Indian Acad. Sci. (Anim. Sci.) 91: 417-422.

Renaud O. \& Victoria-Feser M.P. 2010: A robust coefficient of determination for regression. - J. Stat. Plann. Infer. 140: $1852-1862$.

R CORE TEAm 2020: R: A Language and Environment for Statistical Computing. R Foundation for Statistical Computing, Vienna, URL: https://www.R-project.org

RHAINDS M. 2020: Variation in wing load of female spruce budworms (Lepidoptera: Tortricidae) during the course of an outbreak: evidence for phenotypic response to habitat deterioration in collapsing populations. - Environ. Entomol. 49: 238-245.

RoHLF F.J. 2006: TpsDig Version 2.10. URL: https://life.bio.sunysb.edu/morph

RoHLF F.J. 2008: TpsUtil Version 1.40. URL: https://life.bio.sunysb.edu/morph

Russell L. 2020: Emmeans: Estimated Marginal Means, Aka Least-squares Means. R Package Version 1.4.6. URL: https:// CRAN.R-project.org/package $=$ emmeans

Schielzeth H. 2010: Simple means to improve the interpretability of regression coefficients. - Methods Ecol. Evol. 1: 103-113.

TAmmaru T., Esperk T. \& Castellanos I. 2002: No evidence for costs of being large in females of Orgyia spp. (Lepidoptera, Lymantriidae): larger is always better. - Oecologia 133: 430438.

Tarasova O.V., Kalashnikova I.I. \& Kuznecsova V.V. 2015: Energy balance of fodder consumption by phyllophagous insects: optimization model. - Sib. Lesn. Zh. 2015(3): 83-92 [in Russian, English abstract].

Tatarinov A.G. \& Dolgin M.M. 1999: Fauna of the European North-East of Russia. Rhopalocera Lepidoptera. Nauka, Saint Petersburg, 183 pp. [in Russian].

Tigreros N. \& DaVIDOWITZ G. 2019: Flight-fecundity tradeoffs in wing-monomorphic insects. - Adv. Insect Physiol. 56: 1-41.

Vshivkova T.A. 2009: Evaluation of food suitability for the gypsy moth (Lymantria dispar L.) neonate larvae. - Forestry Bull. 2009(5): 107-110 [in Russian, English abstract].

Wilson R.J., Brooks S.J. \& Fenberg P.B. 2019: The influence of ecological and life history factors on ectothermic temperaturesize responses: Analysis of three Lycaenidae butterflies (Lepidoptera). - Ecol. Evol. 9: 10305-10316.

YонаI V.J. 1987: High breakdown-point and high efficiency estimates for regression. - Ann. Statist. 15: 642-665.

Zakharova E.Yu., ShKurikhin A.O., Solonkin I.A. \& Oslina T.S. 2020: Effect of host plants on the viability of black-veined white Aporia crataegi L. at low natural population density. Russ. J. Ecol. 51: 549-555.

Received January 13, 2021; revised and accepted June 17, 2021 Published online July 12, 2021

Supplementary material follows (Table S1, Figs S1-S4). 
Table S1. Output of the ordinary least squares linear model for forewing area of $A$. crataegi (covariates are standardised and sum-to-zero parametrisation for categorical factors used).

\begin{tabular}{|c|c|c|c|c|}
\hline Predictors & $\beta \pm S E$ & $95 \% \mathrm{Cl}$ (lower / upper) & $z$ & $p$ \\
\hline Intercept & $307.82 \pm 0.51$ & $306.81 / 308.82$ & 598.7 & $<0.001$ \\
\hline Sex & $18.59 \pm 0.51$ & $17.58 / 19.59$ & 36.2 & $<0.001$ \\
\hline Temperature (May) & $7.64 \pm 0.41$ & $6.82 / 8.45$ & 18.4 & $<0.001$ \\
\hline Temperature (April) & $-2.39 \pm 0.44$ & $-3.26 /-1.53$ & -5.4 & $<0.001$ \\
\hline Rainfall (May) & $2.67 \pm 0.41$ & $1.87 / 3.46$ & 6.6 & $<0.001$ \\
\hline Rainfall (April) & $0.72 \pm 0.43$ & $-0.12 / 1.56$ & 1.7 & 0.09 \\
\hline Outbreak & $-2.89 \pm 0.54$ & $-3.95 /-1.82$ & -5.3 & $<0.001$ \\
\hline Sex * Temperature (May) & $1.32 \pm 0.41$ & $0.50 / 2.13$ & 3.2 & 0.002 \\
\hline Sex * Temperature (April) & $1.23 \pm 0.44$ & $0.36 / 2.09$ & 2.8 & 0.006 \\
\hline Sex * Rainfall (May) & $-0.03 \pm 0.41$ & $-0.82 / 0.77$ & -0.1 & 0.95 \\
\hline Sex * Rainfall (April) & $-0.19 \pm 0.43$ & $-1.03 / 0.64$ & -0.5 & 0.65 \\
\hline Sex * Outbreak & $0.85 \pm 0.54$ & $-0.22 / 1.92$ & 1.6 & 0.12 \\
\hline
\end{tabular}
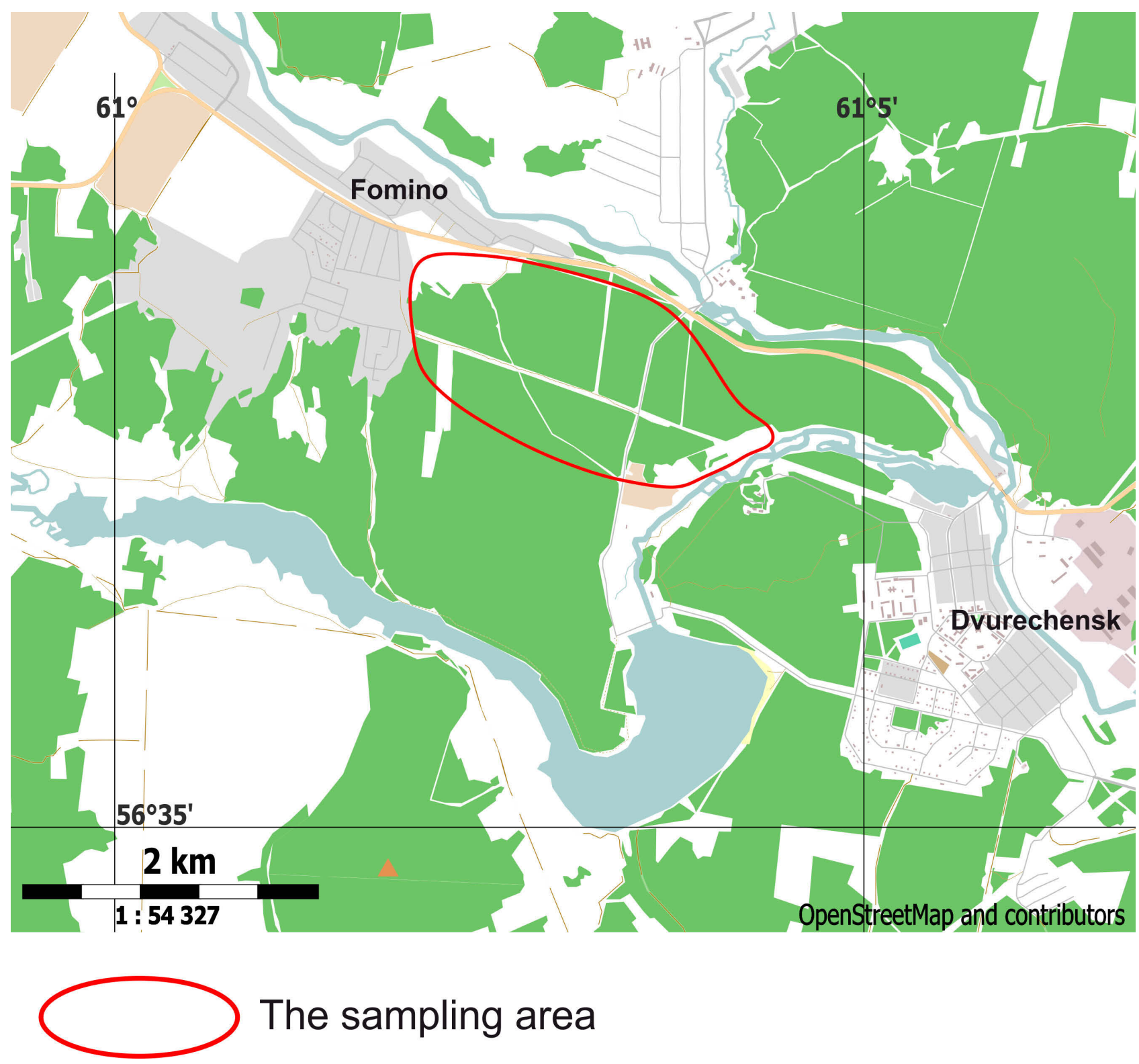

Fig. S1. Map of the area sampled and its vicinity. 

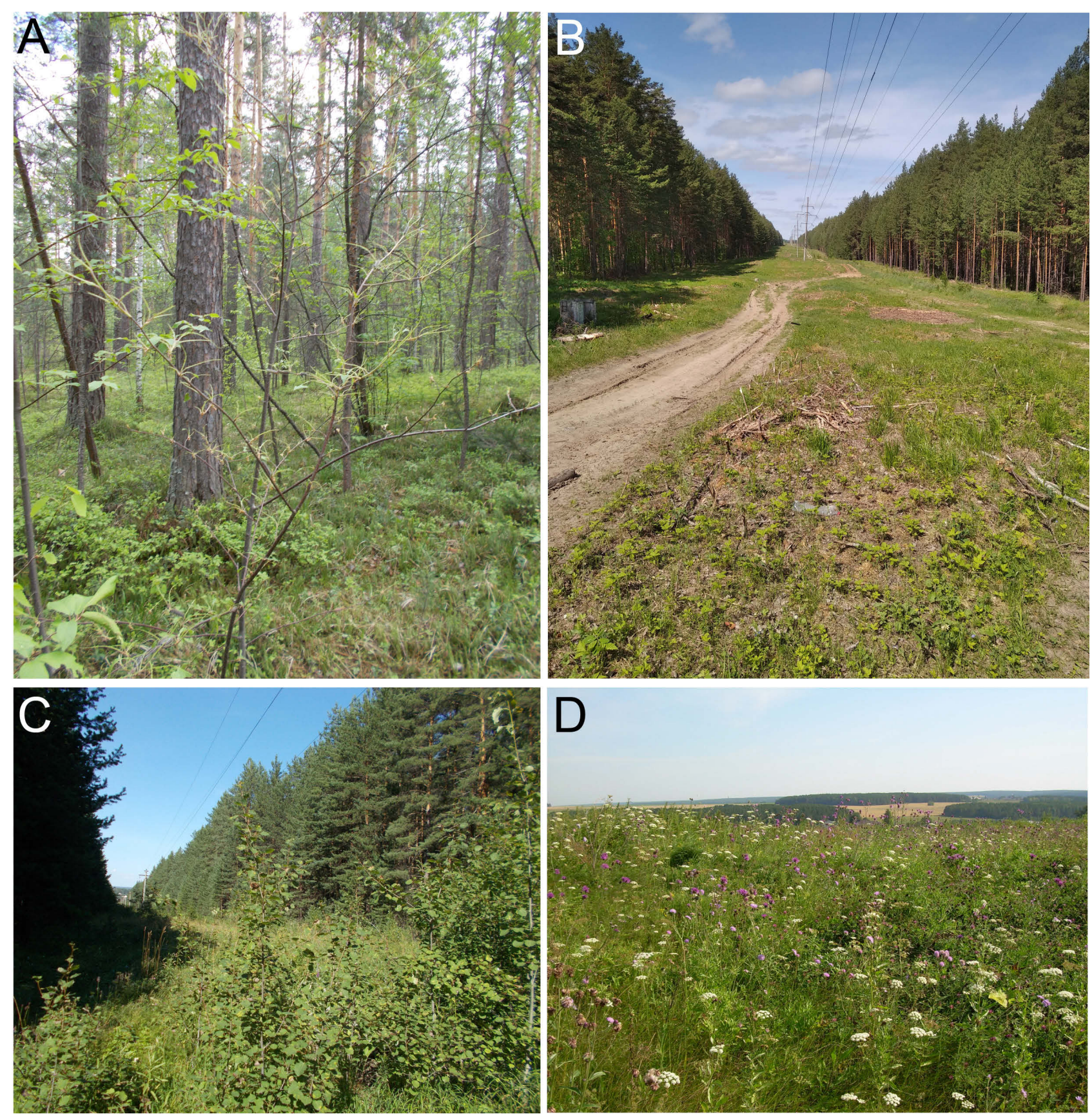

Fig. S2. Photographs of the main habitats in the area sampled: pine forest with low shrubs and herbaceous plants beneath with bird cherry in undergrowth $(A)$, open localities along the power line $(B, C)$ and dry meadow (D). 


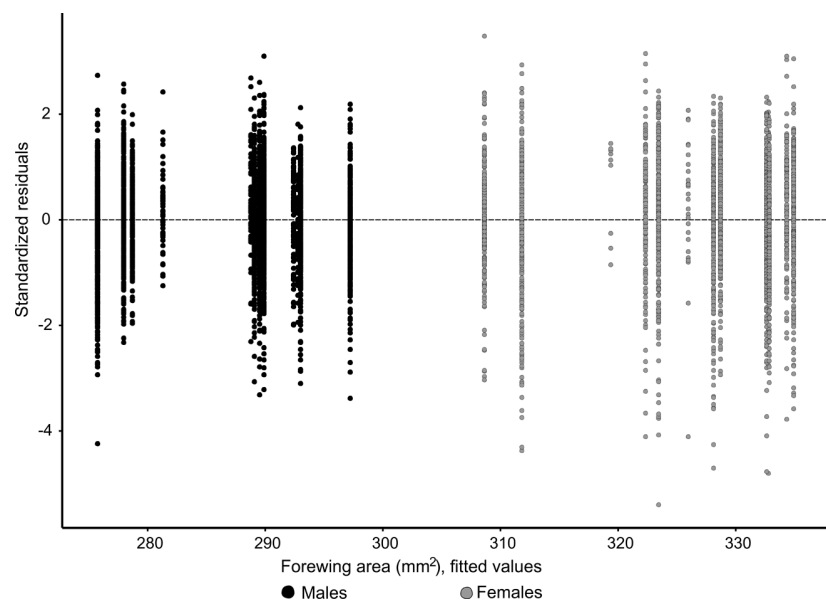

Fig. S3. Relationship between standardised residuals of the ordinary least squares linear model for the forewing area of $A$. crataegi and fitted values.

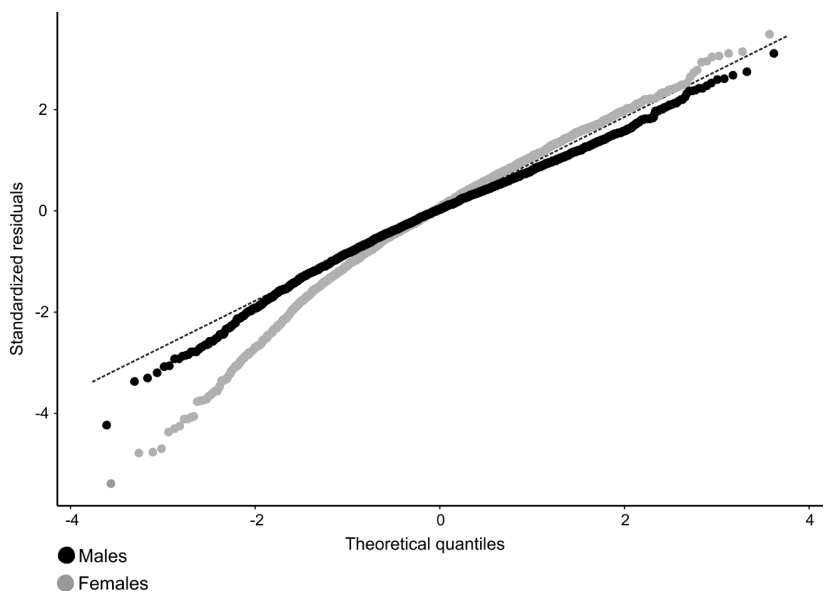

Fig. S4. Relationships between standardised residuals of the ordinary least squares linear model for the forewing area of $A$. crataegi and theoretical quantiles of normal distribution. 